\title{
INTELIGÊNCIA ARTIFICIAL E ESCRITA ACADÊMICA: O QUE NOS RESERVA O ALGORITMO GPT-3?
}

\author{
INTELIGENCIA ARTIFICIAL Y ESCRITURA ACADÉMICA: ¿QUÉ NOS RESERVA \\ EL ALGORITMO GPT-3?
}

\author{
ARTIFICIAL INTELLIGENCE IN ACADEMIC WRITING: WHAT IS IN STORE WITH \\ THE GPT-3 ALGORITHM?
}

Paulo BOA SORTE ${ }^{1}$

Mário André de Freitas FARIAS ${ }^{2}$

Allessandra Elisabeth dos SANTOS ${ }^{3}$

Jefferson do Carmo Andrade SANTOS ${ }^{4}$

Jamile Santos dos Santos Rodrigues DIAS ${ }^{5}$

RESUMO: O objetivo deste estudo é discutir os possíveis impactos da inteligência artificial, com foco no algoritmo GPT-3, na produção escrita acadêmica. Esse algoritmo produz conteúdo com base na aprendizagem de mais de 170 bilhões de parâmetros constantes na rede mundial de computadores. O usuário pode criar, com esse banco de dados, frases, parágrafos, diálogos, imagens e capítulos de livros, que seguem normas gramaticais padronizadas, bastando apenas a inserção de um comando inicial, como "estudos apontam". Realizamos uma pesquisa bibliográfica tomando o objetivo central como ponto de partida para delimitarmos o problema, levantarmos as citações relevantes, aprofundarmos a busca e estabelecermos relação com as fontes obtidas. Os resultados apontam semelhanças de textos produzidos com o uso do GPT-3 a composições humanas, dificultando a identificação da autoria e se diferenciando por trazer referências a fontes utilizadas, o que nos faz pensar acerca dos aspectos éticos, de criatividade e de propriedade intelectual implicados.

PALAVRAS-CHAVE: Inteligência artificial. Escrita acadêmica. Algoritmo GPT-3.

\footnotetext{
${ }^{1}$ Universidade Federal de Sergipe (UFS), São Cristóvão - SE - Brasil. Professor Associado do Departamento de Letras Estrangeiras e Professor Permanente do Programa de Pós-graduação em Educação. Doutorado em Linguística Aplicada e Estudos da Linguagem (PUC-SP). ORCID: https://orcid.org/0000-0002-0785-5998. Email: pauloboasorte@academico.ufs.br

${ }^{2}$ Instituto Federal de Sergipe (IFS), Lagarto - SE - Brasil. Professor de Sistemas de Informação e Professor Permanente do Mestrado Profissional em Educação Tecnológica. Doutorado em Ciência da Computação (UFBA). ORCID: https://orcid.org/0000-0002-4111-1298. E-mail: mario.andre@ifs.edu.br

${ }^{3}$ Universidade Federal de Sergipe (UFS), São Cristóvão - SE - Brasil. Doutoranda no Programa de PósGraduação em Educação. Bolsista CAPES. ORCID: https://orcid.org/0000-0002-9057-2955. E-mail: alle25@academico.ufs.br

${ }^{4}$ Universidade Federal de Sergipe (UFS), São Cristóvão - SE - Brasil. Doutorando no Programa de PósGraduação em Educação. $\quad$ ORCID: https://orcid.org/0000-0002-3299-0948. E-mail: jeffersonandrade06@hotmail.com

${ }^{5}$ Universidade Federal de Sergipe (UFS), São Cristóvão - SE - Brasil. Graduanda em Letras - Português/Inglês. Bolsista de Iniciação Científica COPES/PNAES. ORCID: https://orcid.org/0000-0001-9487-6019. E-mail: letras.jamilesantos@gmail.com
} 
RESUMEN: El objetivo de este estudio es discutir los posibles impactos de la inteligencia artificial, centrándose en el algoritmo GPT-3, en la redacción académica. Este algoritmo produce contenido basado en el aprendizaje de más de 170 mil millones de parámetros contenidos en la World Wide Web, una enorme base de datos que representa aproximadamente el $0.06 \%$ del contenido de Wikipedia. El usuario puede crear, con esta base de datos, oraciones, párrafos, diálogos, imágenes y capítulos de libros, que siguen normas gramaticales estandarizadas, simplemente insertando un comando inicial, como "punto de estudio". Realizamos una búsqueda bibliográfica tomando como punto de partida el objetivo principal y, luego, definimos el problema, planteamos las citas relevantes, profundizamos la búsqueda y establecimos una relación con las fuentes obtenidas. Los resultados apuntan a la similitud de los textos producidos utilizando el GPT-3 con composiciones humanas, dificultando la identificación de autorías y diferenciando al traer referencias a fuentes utilizadas, lo que nos hace pensar en los aspectos éticos, la creatividad y la propiedad intelectual involucrados.

PALABRAS CLAVE: Inteligencia artificial. Escritura académica. Algoritmo GPT-3.

ABSTRACT: The aim of this study is to discuss the possible impacts of artificial intelligence, with a focus on the GPT-3 algorithm, on academic written production. This algorithm produces content based on the learning of more than 170 billion parameters of the World Wide Web, a huge database that represents about $0.06 \%$ of Wikipedia's content. The user can create, with this database, sentences, paragraphs, dialogs, images, and book chapters, which follow standardized grammatical norms, just by inserting an initial command, such as "studies show". We carried out bibliographical research taking the main objective as a starting point and then, we defined the problem, raised the relevant citations, deepened the search, and established a relationship with the sources obtained. The results point to the similarity of texts produced using the GPT-3 to human compositions, making it difficult to identify authorship and differing by bringing references to used sources, which makes us think about the ethical, creativity and intellectual property aspects that may be involved.

KEYWORDS: Artificial intelligence. Academic writing. GPT-3 algorithm.

\section{Introdução}

$\mathrm{Na}$ última década, temos vivenciado o surgimento e a potencialização de conflitos sociais em escalas locais e globais. Frequentemente, os problemas de contextos específicos acabam impactando outros lugares, principalmente quando falamos em países com alto poder econômico. A produção e disseminação de notícias falsas, formas emergentes de comunicação e o impacto dos algoritmos de inteligência artificial na produção de linguagens são alguns desses temas. Temos presenciado, nesse sentido, ações humanas em esferas diversas, como as ambientais e de relações interpessoais. 
A inteligência artificial faz parte da nossa sociedade há décadas. O seu início foi reconhecido ${ }^{6}$ a partir da pesquisa de Turing (1950) e a ideia de que uma máquina pode ter conhecimento equivalente ao do ser humano. Desde então, diversas experiências de inteligência artificial vêm sendo utilizadas, em nosso cotidiano, com o intuito de direcionar as nossas experiências. Alguns exemplos podem ser verificados: em pedidos de transporte por aplicativo que constrói uma estrutura decisória para escolher a melhor opção de motorista, analisando uma série de variáveis (localização, perfil do solicitante, avaliação do motorista, etc.); quando buscamos relacionamentos on-line por meio de multiplataformas de localização de pessoas - elas analisam, além de informações de perfil informadas pelo usuário, dados dos históricos de outras combinações e localizam pessoas geograficamente próximas; quando usamos um robô varredor inteligente, usamos sensores e algoritmos inteligentes; quando navegamos nas redes sociais, os anúncios exibidos têm relação com os itens pesquisados por nós nos motores de busca; ou, ainda, quando interagimos com assistentes virtuais.

Os modelos de algoritmos que, em geral, exploram uma base de dados históricos produzidos por nós são os responsáveis pela personalização da experiência do usuário. Eles recomendam produtos, serviços ou conteúdos por meio de estratégias, como filtragem por associação e filtragem por conteúdo. Ações como essas se tornaram possíveis em virtude do aumento do poder de processamento dos computadores, que permitiu uma maior capacidade do processamento de linguagem natural, aprendizado de máquina, armazenamento e processamento de um grande volume de dados. Modelos de processamento de linguagem natural, a exemplo do algoritmo GPT-3, vêm sendo utilizados para diferentes propósitos, como implementação de robôs de atendimento a clientes e geração automática de textos temáticos.

O modelo algorítmico de inteligência artificial GPT-3 volta-se para a produção escrita na qual textos são gerados a partir de comandos humanos iniciais, a exemplo de uma frase, como "estudos apontam..." ou um comando, "desenhe um círculo". Entretanto, todos os procedimentos seguintes até o produto final ficam a cargo do próprio modelo. O GPT-3 apresenta uma nova dimensão ao universo dos algoritmos de escrita, pois abrange uma variedade de gêneros textuais e vocabulários, graças a um banco de dados de escala ampliada. Além disso, o algoritmo traz a possibilidade de referenciação de citações, o que demanda, assim como em qualquer produção acadêmica, a reflexão sobre criatividade, propriedade

${ }^{6}$ Embora Turing seja considerado o "pai" da Inteligência Artificial, “[a] IA foi antecipada na década de 1840 pela senhora Ada Lovelace. Mais precisamente, ela antecipou uma parte da IA concentrando-se nos símbolos e na lógica, sem vislumbrar as redes neurais ou a IA evolutiva e dinâmica. Tampouco, se voltou para o objetivo psicológico da IA, já que seu interesse era puramente tecnológico" (BODEN, 2020, p. 20, grifos do autor). 
intelectual e autoria. Cabe perguntar, nesse sentido, a quem pertencem esses textos e em que contextos seríamos autorizados a utilizar modelos algorítmicos capazes de produzir textos literários, acadêmicos, manuais de funcionamento, dentre outros.

Diante dos aspectos mencionados, o objetivo geral deste artigo é discutir sobre possíveis impactos da inteligência artificial, especificamente o algoritmo GPT-3, na produção escrita acadêmica. Concebemos, nessa discussão, conceitos de criatividade a partir dos discursos contemporâneos sobre a produção de conteúdo com a utilização de programas de computador, aspectos de propriedade intelectual e autoria dos textos gerados em plataformas de modelos estatísticos de linguagem, além das implicações éticas da utilização do algoritmo GPT-3 para a escrita acadêmica.

Este trabalho é uma pesquisa bibliográfica. Por meio dela, delineamos os aspectos metodológicos que consistem em propor uma pesquisa bibliográfica sobre a temática central deste estudo. Em seguida, exploramos conceitos relacionados à inteligência artificial e aos algoritmos para a produção escrita, especificamente o GPT-3. Logo após, discutimos sentidos acerca da noção de escrita acadêmica na contemporaneidade. Posteriormente, tratamos acerca da ideia de criatividade na comunicação ubíqua. Depois, ponderamos sobre direitos autorais e propriedade intelectual para além dos discursos legais. Por fim, apresentamos algumas considerações e questionamentos oriundos das reflexões empreendidas.

\section{Metodologia da pesquisa}

O tipo de pesquisa adotado para a realização deste estudo foi a bibliográfica. Adotamos a concepção de Paiva (2019, p. 60) acerca desse procedimento metodológico, que distingue a pesquisa bibliográfica da revisão de literatura, pelo fato de que a primeira "vai além da mera busca de informações e não é uma simples compilação dos resultados dessas buscas". Assim, a metodologia selecionada não se resume a uma descrição dos dados nas fontes pesquisadas, necessitando ainda de um estabelecimento de relações e comparações entre as informações.

Partindo das nossas questões de pesquisa, formulamos o título Inteligência artificial e escrita acadêmica: o que nos reserva o algoritmo GPT-3? e selecionamos termos que denotassem seu conteúdo, chegando à delimitação do tema-problema, primeira etapa sugerida por Pizzani et al. (2012) para a realização de uma pesquisa bibliográfica. Com os termos nomeados, tanto em língua portuguesa quanto em língua inglesa, prosseguimos com as etapas subsequentes, também destacadas em grifos: levantamento e fichamento das citações 
relevantes, e aprofundamento da busca, considerando referências teóricas, especialmente, dos últimos três a cinco anos, além de autores como Benzon (2020), sobre inteligência artificial e o algoritmo GPT-3, Burwell (2013), para iniciar a discussão sobre o conceito de criatividade e propriedade intelectual, e Casanave (2019); Russel-Pinson e Harris (2019) para a seção sobre escrita acadêmica.

O passo designado relação das fontes a serem obtidas indica que, nesta pesquisa, utilizamos fontes informacionais dos três tipos classificados por Pizzani et al. (2012): como fontes primárias, artigos e capítulos de livros; as secundárias, artigos de revisão bibliográfica e artigos de divulgação; e as terciárias, os materiais disponíveis on-line em bases de dados. $\mathrm{Na}$ base de dados Portal de Periódicos da CAPES, realizamos a fase de localização das fontes por se tratar de uma base de dados textuais que possibilita a obtenção dos textos completos dos artigos.

Finalizando a sequência de etapas de Pizzani et al. (2012) para a realização de uma pesquisa bibliográfica, realizamos a leitura e sumarização das fontes informacionais. Em seguida, as temáticas foram divididas a partir de tópicos específicos para que a fase final denominada de redação do trabalho iniciasse, como veremos nas seções posteriores.

Pretendemos, com esse roteiro, contribuir com o fomento, em sentido amplo, de um diálogo indisciplinar (MOITA LOPES, 2006) da Linguística Aplicada como uma ciência social (CELANI, 2017; SEALEY; CARTER, 2004) com as bases teóricas das áreas de Comunicação e Mídias, Ciência da Computação e teorias "do digital”, como o fazem Buzato et al. (2013).

Organizamos as próximas seções, a) oferecendo um panorama do nosso entendimento de inteligência artificial e como o algoritmo GPT-3 se insere nele; b) analisando a escrita acadêmica na contemporaneidade, com ênfase para a escrita de trabalhos científicos; c) apontando, no âmbito do discurso contemporâneo da comunicação ubíqua, as possíveis formas de entender o conceito de criatividade; d) pontuando os possíveis olhares sobre direitos autorais e propriedade intelectual de textos gerados em plataformas de modelos estatísticos de linguagem; e) alertando sobre os caminhos que, sem perceber, já começamos a trilhar.

\section{GPT-3: O futuro está aqui?}

A inteligência artificial (IA) foi desenvolvida com a proposta de solucionar problemas que, até então, somente eram resolvidos por humanos. Essa tecnologia diz respeito à 
reprodução artificial da mente humana, simulando o seu aspecto cognitivo, oferecendo predições, tomadas de decisões e repetições dela. Essa reprodução acontece com a leitura e análise do cálculo de dados e códigos recebidos. De acordo com Cope, Kalantzis e Searsmith (2020), a diferença entre a inteligência artificial e a inteligência humana reside no fato de que a IA está abaixo da inteligência humana, no sentido de que ela somente pode calcular a partir dos dados utilizados para aprendizagem. Entretanto, conforme Kaufman e Santaella (2020), o que faz com que a inteligência artificial mostre diferencial em relação à inteligência humana é o fato de que ela realiza tais cálculos de forma mais ágil e certeira, executando, muitas vezes, respostas de forma mais efetiva e assertiva, mas utilizando uma representação do conhecimento.

Com o intuito de compreender o que é Inteligência Artificial, Russel e Norvig (2021) analisaram oito definições. A princípio, as definições foram organizadas baseando-se em dois temas principais: processos de pensamento/raciocínio e comportamento. Posteriormente, foram subdivididas em quatro categorias: sistemas que pensam como humanos, sistemas que agem como humanos, sistemas que pensam racionalmente e sistemas que agem racionalmente. Apesar dessas quatro categorias serem historicamente consideradas relevantes na produção de conhecimento, é notória uma tensão envolvendo as abordagens centradas no humano e aquelas cujo foco está na racionalidade. Os autores explicam que abordagens com foco no humano integram a ciência empírica, trabalhando com hipóteses e experimentos, enquanto abordagens racionalistas reúnem os campos da matemática e da engenharia. Concordando com essa tensão, Wang (2019) também relata, após analisar alguns conceitos sobre IA, não haver consenso entre as definições. Ele afirma que as definições não podem ser entendidas como certas ou erradas, pois cada uma se baseia em critérios teóricos e práticos que influenciam a trajetória da pesquisa.

De acordo com Taulli (2020), existem dois tipos principais de IA: fraca e forte. A forte (ou Artificial General Intelligence - AGI) diz respeito ao raciocínio da inteligência por si própria, ou seja, a máquina realmente "pensa", não somente reproduz linhas de raciocínio a partir do que foi aprendido e absorvido; e a fraca (ou Weak $A I$ ) é a inteligência artificial concentrada em tarefas específicas, ou seja, a máquina pensa, exclusivamente, a partir e sobre a tarefa solicitada a ela, a exemplo da Alexa, Siri ou a Cortana, assistentes virtuais cuja finalidade é executar tarefas propostas pelo usuário por meio do comando de voz, tendo como funcionalidades, agendar compromissos, verificar o tempo, programar despertadores, enviar mensagens ou ajustar configurações. Cabe ressaltar que, de acordo com Kaufman e Santaella (2020, p. 3), "o estágio atual de desenvolvimento da inteligência artificial (IA) é ainda 
restrito". Entretanto, as denominações forte e fraca não fazem jus à potencialidade da tecnologia, que tem mostrado cada vez mais suas capacidades, especialmente no que se refere ao seu subcampo machine learning [aprendizado de máquina, em português].

Recentemente, a startup Uber informou que, buscando inovação, está investindo em machine learning para proteger os seus clientes, identificando riscos com base nos dados coletados pelas milhões de viagens realizadas diariamente. Machine learning (ML) diz respeito ao aprendizado do computador e ao seu melhoramento a partir de uma representação do conhecimento original. O algoritmo aprende a partir de uma base de dados, evolui o aprendizado e, a partir dele, pode tomar decisões. Conforme explicitado por Kaufman e Santaella (2020, p. 4), "O ML explora o estudo e a construção de algoritmos que, seguindo instruções, fazem previsões ou tomam decisões baseadas em dados - modelos elaborados a partir de amostras". Esse processo acontece pela coleta de dados e pela utilização de técnicas estatísticas.

O ML possui tipos diferentes de aprendizado, como o método semi-supervisionado, o método por reforço, e, por fim, o método que é mais comumente utilizado, o método supervisionado (DOMINGOS, 2012; JORDAN; MITCHELL, 2020), em que são adotadas abordagens sistemáticas tais como: classificadores de spam, reconhecedor de imagens e diagnósticos médicos, em que os dados selecionados assumem uma relação de pares com o objetivo de produzir uma previsão em resposta a uma consulta (JORDAN; MITCHELL, 2020; TAULLI, 2020).

Como uma subárea do ML, encontramos a tecnologia intitulada deep learning (DL), cuja tradução significa aprendizado profundo. Nesse sistema, são utilizadas redes neurais que imitam o cérebro humano e que processam grande quantidade de dados, aprofundando o seu aprendizado (MUTHUKRISHNAN, 2020; TAULLI, 2020). O DL firmou-se a partir do "crescimento exponencial dos dados e maior capacidade computacional" (KAUFMAN; SANTAELLA, 2020, p. 4), sendo um modelo avançado e com um tempo otimizado de treinamento. $\mathrm{O}$ modelo estatístico DL mostrou-se muito produtivo com relação às estruturas de dados, conseguindo processar reconhecimentos de imagens de forma mais efetiva bem como identificar e reconhecer a fala, dentre muitos outros aspectos. Segundo Lecun, Bengio e Hinton (2015), o destaque do DL está no fato de que os aprendizados realizados por ele não foram feitos por humanos, mas sim aprendidos a partir de análise de dados. A figura 1 mostra de que forma a Inteligência Artificial, o machine learning e o deep learning se relacionam. 
Figura 1 - Relação entre a IA, ML e DL

Fonte: Muthukrishnan et al. (2020, p. 2)

\section{Artificial Intelligence}

\section{Machine Learning}

\section{Deep Learning}

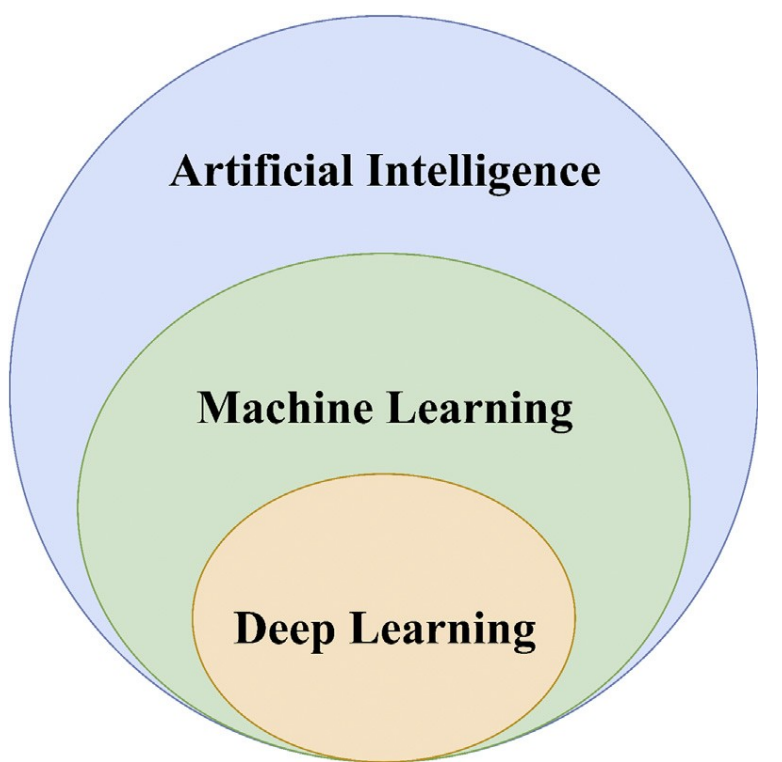

A figura anterior mostra o macro contexto da atuação das máquinas, a inteligência artificial, cujo intuito é o aprendizado para reproduzir ações humanas caracterizadas por “inteligentes", como tomada de decisão e raciocínio. Como integrante desse campo está o machine learning, com modelos computacionais desenvolvidos com base em estratégias de predição por meio de análise de dados. Diretamente conectada à ampliação do acesso a dados, surge uma subárea do aprendizado de máquina, o deep learning, e que, pela presença de inúmeras camadas ocultas na rede neural, possibilita a identificação de padrões que desafiariam o próprio humano. Um exemplo do uso do DL, em nosso cotidiano, é a transcrição da linguagem falada de maneira automática, normalmente denominada Reconhecimento Automático da Fala (Automatic Speech Recognition, em inglês). O aprendizado profundo registra as palavras mais utilizadas bem como as gírias ou siglas que fazem parte do nosso repertório comunicativo.

Dentre os modelos estatísticos de linguagem, foi desenvolvido o GPT-3, algoritmo que utiliza o DL e que foi desenvolvido pela OpenAI, empresa estadunidense fundada em 2015, voltada para pesquisa e desenvolvimento em Inteligência Artificial. Tanto o GPT-3 quanto suas versões anteriores, GPT-1 e GPT-2, são sistemas que produzem elementos textuais em resposta a um comando. Por produção, não cabe a ideia de que ele entende aquilo como uma mente humana, afinal, mesmo os comandos dados e ensinados são realizados por meio da imitação da inteligência humana. O GPT-2, antecessor do GPT-3, possui a capacidade de armazenamento em 1.5 bilhões de parâmetros e tem a capacidade de predizer palavras a partir 
de um comando inicial. Já o GPT-3 é maior que o GPT-2, possuindo 175 bilhões de parâmetros. Para termos uma noção mais clara da dimensão desse algoritmo, os dados da Wikipédia, que englobam cerca de 6 milhões de artigos, representam, somente, $0,06 \%$ dos dados treinados pelo GPT-3. Os elementos textuais criados pelo sistema incluem livros reescritos a partir da introdução de seu autor, conversas com personalidades fictícias ou não, vivas ou não, a partir do aprendizado realizado pelo programa (VINCENT, 2020). Com um banco de dados até 100 vezes maior do que o dos seus antecessores, podemos considerar inúmeras possibilidades para a linguagem, para o aprendizado da máquina e para a maneira como eles se relacionam.

Cabe ressaltar que, conforme explicitado por Ferrari (2008), o computador entende a linguagem passada pelo ser humano quando realizada por meio de linguagem comum do computador com a máquina. Dessa forma, o GPT-3 não consegue criar nem expressar opiniões subjetivas do mundo como um ser humano, uma vez que a subjetividade humana vai além do aprendizado do algoritmo. O que o programa faz é produzir conteúdo com base em seu sentido sintático, e não semântico. Ainda que se criem textos, diálogos ou mesmo capítulos de livros seguindo normas gramaticais padronizadas, o algoritmo não terá a interpretação subjetiva. Conforme explicitado por Benzon (2020), máquinas aprendem a nossa linguagem somente da forma como nós a passamos para elas. Isso quer dizer que, no que diz respeito aos milhões de significados que nossa linguagem possui, o GPT-3 responde e produz somente o texto no que se refere ao significante. De acordo com Lecun (2018 apud KAUFMAN; SANTAELLA, 2020, p. 3), esses sistemas "não têm a capacidade de compreender o funcionamento do mundo a partir da observação (conceitos como tridimensionalidade, movimentação e permanência dos objetos, gravidade, inércia e rigidez dentre outros)". Portanto, é explicitado que, embora ele produza textos, não entende o que está sendo escrito.

Ainda que seja comum pensar no computador, ou mesmo no GPT-3, como uma máquina de superinteligência (BENZON, 2020; FERRARI, 2008), há de se considerar que o seu conhecimento advém dos registros do seu programador. Esse fato é ressaltado por Benzon (2020), ao afirmar que a produção gerada pela ferramenta é somente uma representação da interação entre o ser humano e o mundo, isto é, todo o significado atribuído às produções do GPT-3 é o significado dado pelo próprio leitor. Isso não significa que o GPT-3 não venha a provocar uma mudança no modo de pensarmos as linguagens e tecnologias. Quando falamos sobre o GPT-3 e toda a sua potencialidade, estamos considerando, conforme exemplificado por Vincent (2020), novas possibilidades para a escrita, para o campo criativo, otimizações de 
tempo e inúmeros recursos em constante expansão - um impacto que poderá ser observado na produção de trabalhos acadêmicos.

\section{Escrita acadêmica na contemporaneidade}

A produção de trabalhos acadêmicos se caracteriza por um processo permeado por ansiedade, angústia e estresse, tanto para o discente redigindo em segunda língua quanto para aquele escrevendo em sua língua materna (CASANAVE, 2019; RUSSEL-PINSON; HARRIS, 2019). O processo de escrita pode ser impactado por demandas de trabalho, conflitos familiares, leituras pendentes, falta de imersão na temática e desgastes com atraso de questões burocráticas.

Os pontos mencionados acima são semelhantes aos fatores causadores de estresse elencados por Russell-Pinson e Harris (2019), como: perfeccionismo, conflito de prioridades, escassez de tempo, ansiedade, desafios na relação com o orientador, autossabotagem por meio de hábitos cognitivos negativos e questões pessoais. Esses aspectos influenciam a postura adotada pelo estudante ao longo da escrita, o que pode levar ao desenvolvimento do fenômeno do impostor (HUTCHINS, 2015). Para os autores, algumas intervenções podem ser decisivas para amenizar esses fatores: o reconhecimento dos sinais de estresse e desgaste, o desenvolvimento de grupos de suporte, orientação adequada a cada fase da escrita acadêmica e acompanhamento psicológico ou terapêutico.

Discentes e orientadores precisam pensar sobre o que se espera de uma escrita acadêmica. Questões como revisão gramatical, estrutura consistente de parágrafos, fundamentação relevante ao tema abordado e adequação teórico-metodológica fazem parte do rigor científico. Sendo assim, a produção deve ser desenvolvida com coesão e coerência, seja no domínio do texto em si ou dos conceitos abordados. A preocupação com esses fatores não se refere, ao menos, apenas, a um preciosismo acadêmico, uma vez que o valor científico necessita de conexão entre períodos, parágrafos e seções.

Dessa forma, a proficiência linguística no idioma que o pesquisador disserta interfere no processo e no resultado da escrita, havendo, por sua vez, esforço e ausência de confiança no caso dessa redação ser em segunda língua. No entanto, Casanave (2019) afirma que mesmo os acadêmicos cujo domínio na língua materna seja suficiente apresentam a preocupação com aspectos formais da linguagem e proficiência diante das exigências de uma produção acadêmica. A autora acrescenta que, como uma tese é a escrita mais relevante na vida acadêmica de um aluno, ela impacta não somente a sua reputação como também a do seu 
orientador. As altas e irreais expectativas projetadas pelos discentes acerca do nível de escrita de uma tese geram ansiedade e prejudicam a qualidade da pesquisa podendo, inclusive, interferir na possível contribuição desse estudo para a comunidade acadêmica e para a sociedade.

A escrita acadêmica, com destaque para os trabalhos em ciências humanas, envolve autoria. Pensar nesse aspecto demanda estar atento para o engajamento do escritor no processo de criação intelectual, o que requer posicionamento em vez da imposição de uma suposta neutralidade. A autoria está relacionada à demarcação da identidade do escritor na produção, assim como a preocupação com a entrega de um trabalho inédito e livre de problemas envolvendo plágio.

Alcançar expertise para a escrita de um trabalho acadêmico requer anos de dedicação e esforço. Na visão de Casanave (2019), os anos de estudo em um doutorado, por exemplo, dificilmente garantem que todos os pesquisadores atinjam esse objetivo. A autora chama atenção para o significado dessa expertise, não se resumindo ao domínio de conteúdos acerca das regras linguísticas e textuais ou sobre métodos de pesquisa, mas também à performance de uma expertise ainda não incorporada. Thompson (2012) corrobora a necessidade de o pesquisador apresentar autoria e posicionamento ao longo da escrita e demonstrar também uma performance que convença o ambiente acadêmico nada neutro.

A escrita de trabalhos acadêmicos em nível de graduação e pós-graduação tem sido atravessada por fatores sociais cada vez mais salientes. Como as universidades estão gradativamente ampliando o acesso de grupos diversificados, os conflitos profissionais, familiares e educacionais que impactam diretamente a qualidade da escrita têm sido potencializados (MADDEN, 2016). Não queremos afirmar que esses mesmos conflitos não eram enfrentados previamente, mas vale destacar que, na contemporaneidade, essas questões se intensificam, uma vez que o nível de acesso a bens de consumo e sobrevivência entre as classes sociais ainda é permeado por abismos.

Todos esses fatores têm impactado a produção da escrita acadêmica. Por conta da disseminação crescente de ideologias neoliberais, nas quais os investimentos em ciências humanas tendem a diminuir, estudantes têm experienciado dificuldades, como a diminuição da oferta de bolsas em programas de pós-graduação e a impossibilidade de afastamento ou redução na carga horária das atividades profissionais para o cumprimento dos créditos acadêmicos.

Os autores mencionados, nesta seção, recomendam que o desenvolvimento da escrita acadêmica na contemporaneidade ocorra em grupos de suporte para escrita, realizando 
atividades, como revisão em pares, feedback não avaliativo, orientação formal e informal por mentores e suporte emocional. Tais atividades funcionam como uma extensão da orientação e potencializam o desenvolvimento de autoria do pesquisador.

Tentando estabelecer um contraponto em relação a essas orientações, apresentamos, na seção seguinte, uma discussão sobre a criatividade no discurso contemporâneo, em tempos de comunicação ubíqua, aspecto que o algoritmo GPT-3 pode desestabilizar, especialmente quando se trata da ideia clássica de produção textual.

\section{A criatividade no discurso contemporâneo em tempos de comunicação ubíqua}

Em um cenário de ubiquidade, a maior parte das interações e experiências tem ocorrido amplamente em meios digitais, havendo construção de sentidos e identidades com recursos multimodais e por meio de processos coletivos e transformativos. Essas possibilidades de autoexpressão podem acontecer de uma forma imaginativa e criativa nos processos de expressão escrita mais formais e concretizadas, principalmente, em práticas de remix (fan fiction, mash-up musicais, machinima etc.), assim como em contextos de estudo, trabalho e entretenimento (BURWELL, 2013; KNOBEL, 2015).

A criatividade pode ser entendida como uma habilidade crucial para compor a força transformativa da lógica econômica, que vem à tona, especialmente, no cenário desafiador atribuído às constantes e impactantes mudanças acarretadas pelas tecnologias digitais (FLORIDA, 2012). Diante desse cenário, Burwell (2013) e Knobel (2015) apontam para a transição do conceito de criatividade, a princípio, focado no criar individual e solitário para uma conceituação de criatividade como uma produção social, coletiva e promotora de construção de sentidos.

Neves-Pereira (2018) explica a trajetória dos conceitos de criatividade na contemporaneidade a partir do que denomina "posicionamento conceitual", a despeito da ausência de uniformidade quanto à interpretação desse fenômeno. Para a autora, é relevante promover o diálogo acerca das distintas posições conceituais com o intuito de se possibilitar criatividade na pesquisa científica, além de defender que "[estudar] criatividade é muito importante, mas ser criativo, na ciência, parece uma proposta de maior relevância" (NEVESPEREIRA, 2018, p. 5). Quatro posicionamentos conceituais são marcantes nessa discussão e abarcam elementos relacionados à inovação, ao sistema e de caráter sócio-histórico e psicossociocultural. 
O primeiro deles é a chamada posição conceitual padrão, de Stein (1953), para quem a criatividade é vista como um processo em que um indivíduo cria algo útil e inovador. Embora esse conceito tenha sido bem aceito - servindo, inclusive, como base para os testes de Torrance (1996) que medem características do pensamento criativo, e para outras linhas de pesquisa sobre personalidade criativa, processo criativo e produto criativo - são visíveis as divergências acerca das perspectivas dos aspectos de utilidade e novidade nas investigações.

Com isso, surge um segundo posicionamento conceitual, a posição sistêmica de Csikszentmihalyi (2014), cuja compreensão de criatividade é transferida do ato do criar individual, visto mais como um fenômeno mental para um processo permeado por significações de aspectos culturais e sociais. A ideia, segundo Neves-Pereira (2018, p. 7), é de que a criatividade advém do julgamento e aceitação de determinados grupos de indivíduos ao invés de um "produto de indivíduos singulares, em ações individuais [...] Ela sempre vai gerar modificações em todas as instâncias envolvidas [...] o sujeito, seu núcleo social e seu nicho cultural".

A terceira posição conceitual sócio-histórica da criatividade é baseada nas contribuições de Vygotsky (1990) para a Psicologia, cuja abordagem modifica as formas de compreensão dos processos de desenvolvimento humano e aprendizagem. O desenvolvimento humano é redefinido de um "processo evolutivo interno a processo sócio-histórico" (VYGOTSKY, 1990, p. 8), alterando a concepção de criatividade como fenômeno humano. Nessa posição, há um modelo denominado de Imaginação Criativa, oriunda dos estudos de Vygotsky acerca da criatividade, não se identificando, entretanto, um conceito oficial. Esse modelo não destaca as questões de utilidade ou originalidade, entendendo, por sua vez, o fenômeno criatividade integrante de processos complexos e intrínsecos a outras funções psicológicas humanas.

O quarto e último posicionamento abordado por Neves-Pereira (2018) se fundamenta em Vygotsky (1990), mas apresenta uma definição objetiva de criatividade. A posição conceitual sociocultural de Glaveanu (2010) compreende criatividade como um processo psicossociocultural, que acontece em um espaço intersubjetivo e por meios de interações sociais dialógicas, na tentativa de entender como ocorrem as transformações de elementos culturais simbólicos em novos e originais, ou seja, produtos criativos. Preocupados com essas transformações ocorridas no cenário da Sociedade de Informação para a Sociedade PósInformação, Glaveanu et al. (2019) elaboram um manifesto como uma resposta ao ritmo acelerado da presença de variadas formas de inteligência artificial, apontando para a criatividade como um aspecto necessário para a dignidade e sobrevivência da espécie humana. 
Os autores reafirmam a visão de criatividade como um fenômeno sociocultural, no qual mente e cultura são intrínsecas e continuamente se moldam entre si, e que contribuições de novos estudos sobre o tema impactam diretamente organizações e escolas.

Refletindo sobre a escrita no contexto acadêmico, visualizamos tentativas para motivação de uma escrita individual, criativa e argumentativa, porém, uma escrita com tecnologias analógicas, na qual o aluno pouco se identifica, pois esse modo de escrever tende a não mais representá-lo. Se o cenário das culturas digitais oferece liberdade e multimodos para expressão, via imagens, sons, vídeos, e ainda sem restringir a sua construção de sentido individual e de comunidade, adolescentes e jovens se encorajam, então, a expressar suas visões de mundo, representativas de suas identidades em cenários da comunicação ubíqua, isto é, com dispositivos móveis conectados à internet, podendo ser realizado a qualquer hora e em qualquer lugar.

O escrever nas mídias digitais, portanto, delineia-se como um processo criativo de forma coletiva e transformativa. Burwell (2013) destaca a relevância do educar adolescentes e jovens para pensar criticamente acerca do poder da mídia, reconhecendo o potencial pedagógico de práticas como o remix. Nessa discussão, ela concorda que as identidades das pessoas jovens e suas visões de mundo estão sendo cada vez mais moldadas por meio de textos e interações digitais, enfatizando a introdução de conversas sobre representação, apropriação, criatividade e propriedade intelectual no ambiente de sala de aula.

Pensando nos cenários contemporâneos sobre criatividade na produção textual, apresentamos, na seção seguinte, algumas discussões sobre direitos autorais e propriedade intelectual. Essas duas temáticas possuem forte apelo no campo jurídico no que concerne à garantia de reconhecimento dos autores e inventores de artefatos diversos da sociedade, contemplando o domínio artístico, literário, industrial e científico de modo geral. O nosso foco, porém, recai sobre a problematização da noção de autoria/criação em tempos em que os discursos sobre criatividade têm sido desestabilizados.

\section{Direitos autorais e propriedade intelectual: um olhar restrito às leis?}

A Declaração Universal dos Direitos Humanos (ONU, 1948), no artigo 27, menciona que toda pessoa tem o direito de usufruir das produções culturais e de ter salvaguarda dos interesses morais e materiais oriundos de sua autoria. Essa referência, apesar de não ser normativa, coloca em destaque questões de propriedade intelectual, especificamente no que concerne a direitos autorais. 
No contexto brasileiro, temos duas leis que regulamentam a propriedade intelectual: a Lei n 9.279 (BRASIL, 1996), que normatiza sobre direitos e deveres concernentes à propriedade industrial, abrangendo a concessão de patentes, o registro de marcas e o reconhecimento de invenções; e a Lei $n^{0} 9.610$ (BRASIL, 1998), que legisla sobre direitos autorais, envolvendo a produção artística, literária e demais obras de criação do espírito. Essas obras estão vinculadas ao intelecto e, em muitos casos, não estão atreladas à valorização da subjetividade do autor.

Nesta seção, o olhar que lançamos em relação à escrita na contemporaneidade parte de dois pontos principais: uma discussão relacionada a direitos autorais para além das leis e a problematização do que tem sido entendido como produção de textos. Em face das possibilidades ofertadas por plataformas e dispositivos digitais, como o GPT-3, a escrita tem sido cada vez mais expressa com um fenômeno multimodal. Diante disso, pensar em produção textual apenas no domínio tipográfico significa negligenciar que aspectos sonoros, visuais e táteis, por exemplo, impactam a leitura, a escrita e, portanto, a construção de sentidos. Partindo dessa perspectiva, pensamos que a efervescência dos ambientes digitais coloca em pauta a necessidade de repensarmos o que entendemos por propriedade intelectual, pois o pertencimento dos textos vai além dos domínios jurídicos. Neste texto, apontamos uma problematização da noção de autoria a partir do diálogo entre as normas apresentadas legislação brasileira e discussões nos campos da educação e linguagem que ressignificam os conceitos de autoria.

Se levarmos em consideração a Lei Brasileira de Direitos Autorais, em seu artigo 11, o autor é definido como aquele que cria obras literárias, artísticas e científicas. Tal definição está direcionada, prioritariamente, a um processo de produção individual, aspecto divergente daquele apontado por Jenkins (2009) em que a produção textual na contemporaneidade está baseada em uma cultura participativa. A autoria pensada à luz da cultura participativa tenciona pensar que toda criação é inspirada em algo e que o caráter inédito não recai necessariamente em algo inexistente, mas no empreendimento de um novo olhar. Nessa acepção, de acordo com Burwell (2013), a produção textual está pautada em aspectos de representação, apropriação, criatividade e propriedade intelectual.

A escrita acadêmica na contemporaneidade, principalmente se mediada por bases pósestruturalistas, precisa levar em conta o conceito de apropriação ética, o que demanda que a autoria não seja vista apenas como um processo baseado em leis. Entendemos a apropriação ética como a preocupação em reconhecer que todo processo de criação parte de um contexto específico, se ancora em outras produções e reconhece as referências utilizadas. Diante das 
possibilidades tecnológicas da contemporaneidade, Burwell (2013) defende a existência de espaços para discussão de textos e práticas digitais na educação. Pensamos, ainda, que a educação contemporânea demanda pensar a relação, em muitos casos, convergente, entre textos digitais e não-digitais.

Ilustramos, logo abaixo, uma noção ampla acerca da propriedade intelectual, entendida não apenas como um aspecto restrito a leis. Apresentamos a propriedade intelectual a partir do que é apontado na legislação, mas ampliamos a discussão ao passo que analisamos tal conceito pela perspectiva da educação e da linguagem por meio de olhares pós-estruturalistas. Dessa forma, apontamos, na figura abaixo, a apropriação ética e a criatividade como elementos relevantes na discussão sobre o pertencimento dos textos produzidos na atualidade.

Figura 2 - Mapa sobre propriedade intelectual

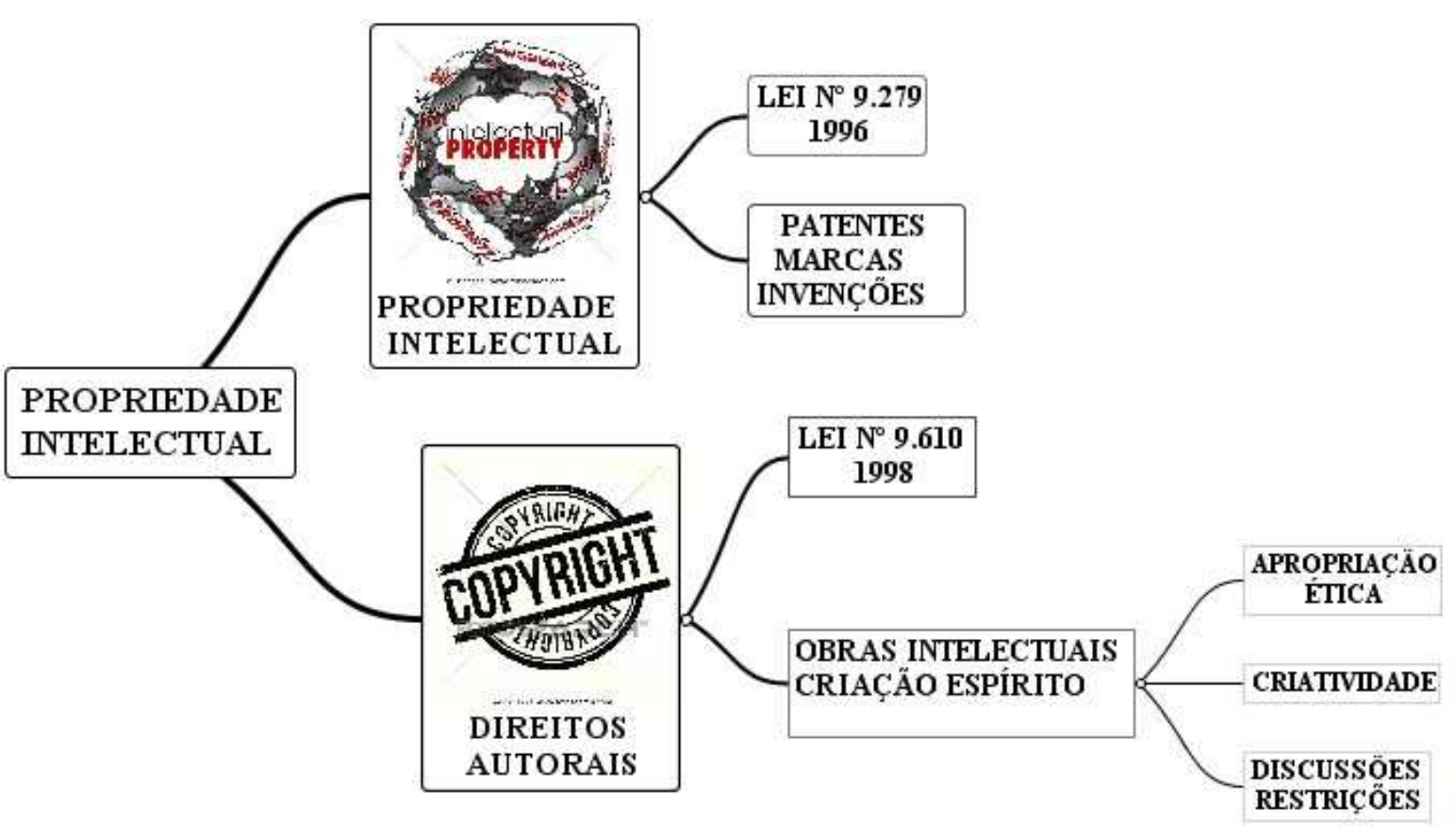

Fonte: Elaboração dos autores

Seguindo uma perspectiva ampliada sobre propriedade intelectual, assim como apresentamos na imagem acima, Boa Sorte (2018) aponta que a noção de expressão escrita restrita à produção de textos tipográficos precisa ser questionada, uma vez que, levando em conta uma linha multimodal, os conceitos de escrita e de texto têm sido expandidos, tanto no produto em si quanto nos sentidos que construímos (COPE; KALANTZIS, 2000). Com isso, a leitura também passa a ser entendida como coautoria, ao passo que começa a ser vista como construção de sentidos (SOUZA, 2018). Os textos, portanto, passam a ser visualizados como 
produtos inacabados e suscetíveis a interpretações diversas, resultando, assim, em textos diferentes para cada contexto e leitor-coautor. Além disso, suportes variados, a exemplo de dispositivos de áudio e vídeo, passam a possibilitar a produção textual, problematizando a ideia de que um texto resulta apenas da escrita em papel ou em programas de edição tipográfica.

Nessa direção, a produção textual tem sido cada vez mais pensada à luz da criação de remixes. Práticas de remixagem têm se tornado aspectos marcantes em tempos de culturas digitais, pois passaram a ser vistas além do domínio do entretenimento. Em breves palavras, remixes podem ser conceituados como textos produzidos de forma colaborativa por meio de cópia, combinação, manipulação ou transformação de conteúdo que podem potencializar as identidades e as práticas sociais dos seus criadores (BURWELL, 2013). Apesar de apontarmos as práticas de remixes como significativas para o campo educacional, não defendemos o empreendimento de olhares contemplativos; tais práticas tencionam um direcionamento crítico, o que representa pensar sobre os impactos éticos dessas criações na sociedade. Nesse sentido, levando em consideração Janks (2010; 2014) e Burwell (2013), os textos precisam ser vistos pelo prisma da análise crítica, a qual atenta para questões de autoria, criatividade, poder e justiça social.

\section{Ética, algoritmo GPT-3 e a escrita acadêmica: aonde estamos indo?}

Essa tecnologia já está em curso. A linguagem é constantemente modificada pelos usos que fazemos das tecnologias. Ainda que o modelo precise ser aprimorado, conforme explicita Vincent (2020), o que realmente faz do GPT-3 uma tecnologia diferenciada é a sua capacidade de gerenciar bilhões de dados bem como a sua formulação das respostas, produzindo textos por conta própria, uma vez que o sistema aprendeu e avançou mais do que suas versões anteriores. Escritas acadêmicas podem ser produzidas, propagando o conhecimento para cada vez mais pesquisadores, alunos, professores e leigos em determinadas áreas.

Há que considerar a quem a tecnologia vai servir. Em testes realizados (VINCENT, 2020) com o GPT-3, ele produziu séries de tweets racistas e machistas, espelhando as postagens de quem atua nas redes. Como explicam Brown et al. (2020), não há como afirmar que a própria tecnologia simplesmente criou tais opiniões, e sim que as reproduziu dos dados analisados em seu treinamento. 
Considerando todas as mudanças ocorridas com a IA em seu curso, cada vez mais máquinas têm sido aprimoradas e ensinadas um pouco mais sobre nós e a nossa forma de ver o mundo. Assim como a linguagem é dinâmica e se remodela no decorrer dos anos, também a tecnologia o faz. No presente do GPT-3, há infinitas possibilidades para o ensino e aprendizado, para as produções científicas, literárias, ficcionais, para o ensino básico e superior, público e privado. Essa já é uma realidade, sendo que, daqui para frente, a tendência é que o algoritmo GPT-3 seja aprimorado e se desenvolva, aprendendo, expandindo todas as suas potencialidades e oferecendo uma versão avançada daquilo que já é possível de ser visualizado e utilizado.

As discussões apresentadas neste artigo perpassam dois conflitos latentes: as ponderações são preliminares, mas, ao mesmo tempo, estão entregues ao caráter efêmero dos estudos no campo das tecnologias. Por outro lado, posto que o acesso ao GPT-3 está limitado aos desenvolvedores do sistema, aos especialistas em gerenciamento de dados e a pesquisadores, propomos uma tentativa de reflexão prévia sobre os impactos que esse modelo algorítmico pode empregar na escrita acadêmica quando for liberado a todos os usuários. A nossa intenção, portanto, não é apontar passos a serem seguidos por professores, especialistas em escrita acadêmica ou entusiastas do campo da inteligência artificial. Propomos pensar sobre os impactos que podem ocorrer a partir do uso desse algoritmo, em tempos que a autoria se torna um fenômeno em constante desestabilização e reestruturação.

Ao longo do texto, discutimos sobre temáticas que nos pareceram relevantes à problematização da escrita acadêmica na contemporaneidade, dentre elas, criatividade, ética e propriedade intelectual. Em nossa concepção, o algoritmo GPT-3 pode apresentar dilemas que nos tencionam à reflexão acerca do que entendemos por autoria. Por outro lado, pensamos que essa ponderação não está direcionada a analisar a autoria apenas a partir de direcionamentos canônicos. Como a produção acadêmica tem sido atravessada pelos impactos das culturas digitais, consideramos a relevância de pensarmos sobre os impactos dos modelos algorítmicos de produção escrita nos sentidos que construímos atualmente sobre autoria, criatividade e ética.

AGRADECIMENTOS: À Coordenação de Aperfeiçoamento de Pessoal de Nível Superior (CAPES) e à Universidade Federal de Sergipe (COPES/PNAES) pelo fomento. 


\section{REFERÊNCIAS}

BENZON, W. GPT-3: Waterloo or rubicon? Here be Dragons. Cognitive and Neuroscience, ago. 2020. Disponível em: https://www.researchgate.net/publication/343444766_GPT3_Waterloo_or_Rubicon_Here_be_Dragons. Acesso em: 6 out. 2020.

BOA SORTE, P. Remixes e expressão escrita em língua inglesa. In: JORDÃO, C. M.; MARTINEZ, J.; MONTE MÓR, W. (org.). Letramentos em prática na formação inicial de professores de inglês. Campinas: Pontes, 2018.

BOA SORTE, P. English teaching assistants in Brazil: conceptions of subject matter, teaching and learning to teach. Revista Tempos e Espaços em Educação, v. 11, p. 227-237, 2018.

BODEN, M. Inteligência artificial: uma brevíssima introdução. São Paulo: Editora Unesp, 2020.

BOTTENTUIT JR., J. B.; MENEZ, M. R. C. S.; WUNSCH, L. P. Aplicativos móveis para a alfabetização e letramento no contexto do ensino fundamental. Tempos e Espaços em Educação, v. 11, n. 01, p. 37-56, 2018.

BRASIL. Lei n. 9.279, de 14 de maio de 1996. Regula direitos e obrigações relativos à propriedade intelectual. Brasília, DF, 15 maio 1996. Disponível em: http://www.planalto.gov.br/ccivil_03/leis/19279.htm. Acesso em: 6 out. 2020.

BRASIL. Lei n. 9.610, de 19 de fevereiro de 1998. Altera, atualiza e consolida a legislação sobre direitos autorais e dá outras providências. Brasília, DF, 20 fev. 1998. Disponível em: http://www.planalto.gov.br/ccivil_03/leis/19610.htm. Acesso em: 6 out. 2020.

BROWN, T. B. et al. Language models are few-shot learners. Cornell University Library. 2020. 75 p. Disponível em: https://arxiv.org/pdf/2005.14165v1.pdf. Acesso em: 30 out. 2020.

BURWELL, C. The pedagogical potential of video remix: critical conversations about culture, creativity and copyright. Journal of Adolescent \& Adult Literacy, v. 57, n. 3, p. 205-213, nov. 2013.

BUZATO, M. E. K. et al. Remix, mashups, paródia e companhia: por uma taxonomia multidimensional da transtextualidade na cultura digital. Revista Brasileira de Linguística Aplicada, Belo Horizonte, v. 13, n. 4, p. 1191-1221, 2013.

CASANAVE, C. P. Performing expertise in doctoral dissertations: thoughts on a fundamental dilemma facing doctoral students and their supervisors. Journal of Second Language Writing, v. 43, n. 1, p. 57-62, 2019.

CELANI, M. A. A. Linguística Aplicada e Transdisciplinaridade. In: FREIRE, M. M. Vias para a pesquisa: reflexões e mediações. São Paulo: Cruzeiro do Sul Educacional - Campus Virtual, 2017.

COPE, B.; KALANTZIS, M.; SEARSMITH, D. Artificial intelligence for education: knowledge and its assessment in AI-enabled learning ecologies. Educational Philosophy 
and Theory, v. 53, n. 12, p. 1229-1245, 2018. Disponível em:

https://doi.org/10.1080/00131857.2020.1728732. Acesso em: 11 nov. 2020.

COPE, B.; KALANTZIS, M. Multiliteracies: literacy learning and the design of social futures. London: Routledge, 2000.

CSIKSZENTMIHALYI, M. Teoria do Flow, pesquisa e aplicações. ComCiência, Campinas, n. 161, set. 2014. Disponível em: http://comciencia.scielo.br/scielo.php?

script $=$ sci_arttext\&pid=S1519-76542014000700010\&lng=en\&nrm=iso. Acesso em: 11 nov. 2020.

DOMINGOS, P. A few useful things to know about machine learning. Communications of the ACM, v. 55, n. 10, p. 78-87, out. 2012.

FERRARI, F.; CECHINEL, C. Introdução a algoritmos e programação. Bagé, RS:

Universidade Federal do Pampa, 2008. Disponível em:

http://www.cristiancechinel.pro.br/my_files/algorithms/bookhtml/apostila-algoritmos.html.

Acesso em: 2 out. 2020.

FLORIDA, R. The rise of the creative class revisited. New York: Basic Books, 2012.

GLAVEANU, V. P. Paradigms in the study of creativity: introducing the perspective of cultural psychology. New Ideas in Psychology, v. 28, n. 1, p. 79-93, abr. 2010. DOI: https://doi.org/10.1016/j.newideapsych.2009.07.007

GLAVEANU, V. P. et al. Advancing creativity theory and research: a social-cultural manifesto. Journal of Creative Behavior, v. 54, n. 3, p. 741-745, 2019. DOI: https://doi.org/ 10.1002/jocb.395

HUTCHINS, H. M. Outing the imposter: a study exploring imposter phenomenon among higher education faculty. New Horizons in Adult Education \& Human Resource Development, v. 27, n. 2, p. 2-12, 2015.

JANKS, H. Reading texts critically. In: JANKS, H. Literacy and power. USA: Routledge, 2010.

JANKS, H. Doing critical literacy: texts and activities for students and teachers. New York: Routledge, 2014.

JENKINS, H. Cultura da convergência. Trad. Susana Alexandria. São Paulo: Aleph, 2009.

JORDAN, M.; MITCHELL, T. Machine learning: trends, perspectives, and prospects. Science, v. 349, p. 255-260, 2020.

KAUFMAN, D.; SANTAELLA, L. O papel dos algoritmos de inteligência artificial nas redes sociais. Revista Famecos, Porto Alegre, v. 27, p. 1-10, jan./dez. 2020.

KNOBEL, M. Imagining beyond the domesticated "new": creative remixings of literacies, community, and place. An analytic review of the research literature. Literacy Research Association Conference Symposium, dez. 2015. 
LECUN, Y.; BENGIO, Y.; HINTON, G. Deep learning. Nature, v. 521, p. 446-444, 27 maio 2015.

MADDEN, S. Introduction: access as praxis for graduate writing. Praxis: Writing Central Journal, v. 14, n. 1, p. 1-8, 2016.

MOITA LOPES, L. P. (org.) Por uma linguística aplicada indisciplinar. São Paulo: Parábola Editorial, 2006.

MUTHUKRISHNAN, N. et al. Brief History of Artificial Intelligence. Neuroimaging Clinics of North America, v. 30, n. 4, p. 393-399, nov. 2018. DOI:

https://doi.org/10.1016/j.nic.2020.07.004

NEVES-PEREIRA, M. C. Posições conceituais em criatividade. Psicologia em Estudo, v. 23, p. 1-15, ago. 2018. DOI: https://doi.org/10.4025/psicolestud.v23i0.39223

ONU. Organização das Nações Unidas. Declaração Universal dos Direitos Humanos. Assembleia Geral das Nações Unidas. Paris, 10 dez. 1948.

PAIVA, V. L. M. O. Manual de pesquisa em estudos linguísticos. São Paulo: Parábola, 2019.

PIZZANI, L. et al. A arte da pesquisa bibliográfica na busca do conhecimento. RDBCI: Revista Digital de Biblioteconomia e Ciência da Informação, Campinas, v. 10, n. 2, p. 53 66, 2012. DOI: https://doi.org/10.20396/rdbci.v10i1.1896

RUSSEL, S. J.; NORVIG, P. Artificial Intelligence: a modern approach. New Jersey. Prentice Hall, 2021.

RUSSELL-PINSON, L.; HARRIS, M. L. Anguish and anxiety, stress and strain: Attending to writers' stress in the dissertation process. Journal of Second Language Writing, v. 43, p. 63-71, 2019.

SEALEY, A.; CARTER, B. Applied Linguistics as social science. London: Continuum, 2004.

SOUZA, M. A. A. Formação de professores de Inglês: buscando caminhos para uma Educação linguística crítica. In: PESSOA, R. R.; SILVESTRE, V. P. V.; MONTE MÓR, W. Perspectivas críticas da Educação linguística no Brasil: trajetórias e práticas de professoras(es) universitárias(os) de Inglês. São Paulo: Pá de Palavra, 2018. p. 163-174.

STEIN, M. Creativity and culture. The Journal of Psychology, v. 36, n. 2, p. 311-22, 1953.

TAULLI, T. Introdução à inteligência artificial: uma abordagem não técnica. 1. ed. São Paulo: Novatec, 2020. 232 p.

THOMPSON, P. Achieving a voice of authority in PhD theses. In: HYLAND, K.; GUINDA, C.S. (Eds.) Stance and voice in written academic genres. UK: Palgrave MacMillan, 2012. p. 119-133. 
THÜRLER, D.; SANTOS, J. L. Um debate sobre a escola como tecnologia político-cultural. Revista Tempos e Espaços em Educação, v. 7, n. 12, p. 29-44, out. 2014. DOI: https://doi.org/10.20952/revtee.v0i0.2950

TORRANCE, T.F. Revelation, creation and law. The Heythrop Journal, v. 37, p. 273-283, 1996.

TURING, A. Computing machinery and intelligence. Mind, v. LIX, n. 236, p. 433-460, out. 1950, Pages, DOI: https://doi.org/10.1093/mind/LIX.236.433

VINCENT, J. Openai's latest breakthrough is astonishingly powerful, but still fighting its flaws:the ultimate autocomplete. The Verge, 2020. Disponível em:

https://www.theverge.com/21346343/gpt-3-explainer-openai-examples-errors-agi-potential. Acesso em: 5 out. 2020.

VYGOTSKY, L. A construção do pensamento e da linguagem. Trad. Paulo Bezerra. São Paulo: Martins Fontes, 1990.

WANG, P. On defining artificial intelligence. Journal of Artificial General Intelligence, v. 10, n. 2, p. 1-37, ago. 2019. DOI: https://doi.org/10.2478/jagi-2019-0002

ZACCHI, V. J. Literacies and digital gaming: negotiating meanings in English language teacher education. Revista Tempos e Espaços em Educação, v. 11, n. 1, p. 153-168, 2018. DOI: https://doi.org/10.20952/revtee.v11i01.9831

\section{Como referenciar este artigo}

BOA SORTE, P.; FARIAS, M. A. F.; SANTOS, A. E.; SANTOS, J. C. A.; DIAS, J. S. S. R. Inteligência artificial e escrita acadêmica: o que nos reserva o algoritmo GPT-3? Rev. EntreLínguas, Araraquara, v. 7, n. 00, e021035, 2021. e-ISSN: 2447-3529. DOI: https://doi.org/10.29051/el.v7i1.15352

Submetido em: 08/08/2021

Revisões requeridas em: 01/09/2021

Aprovado em: 15/09/1021

Publicado em: 08/10/2021 